\title{
The Role of Spiritual Psychology for Holistic Living
}

\begin{abstract}
Ankur Mahida $^{1}$
\section{ABSTRACT}

Many studies have provided evidences that religion and spirituality are positively associated with indicators of mental health. The present research paper is going define the role of spiritual psychology for Holistic living. Holistic living offers a way to balance our life in all areas health, relationships, spirituality, and finances -- to achieve a happier, healthier, and more fulfilling lifestyle. Spirituality includes our perception of us, an adherence to values, of being ethical, and being connected with others, while maintaining a belief system that typically includes some religious dimension. Many spiritual activities like prayer, meditation, reading holy books, charity, yoga, worship and attending spiritual speeches and seminars helps us to balance our emotions, develop healthier thinking patterns and spirituality helps one to discover the trurh, exploring existential questions, doubts and confusion. By doing these activities every day we can have a better life styles and values towards our life. In this global world, spiritual psychology can play very important role for holistic living and there are many practitioner who wished to apply religion and spirituality as a part of treatment.
\end{abstract}

Keywords: Spiritual Psychology, Holistic Living.

Keep your thoughts positive because your thoughts become your words. Keep your words positive because your words become your behaviors. Keep your behaviors positive because your behaviors become your habits. Keep your habits positive because your habits become your values. Keep your values positive because your values become your destiny. -Mahatma Gandhi

The concept Spirituality is a holistic one, which encompasses the physical, emotional, social and the spiritual aspects of an individual. Spirituality is a unified quality of body, mind, heart spirit or soul. Spirituality is one of the most important sources of strength and direction in people's lives. A spiritual side of human nature remains important to Asian lives. A number of important psychologists such as William James, Carl Jung, Gordan Allport and Abraham Maslow have considered spirituality as part of their theory of human behavior. Spirit is a human phenomenon, which exists in almost all persons. It is define spirituality is not an easy task. Spirituality is complex and has many dimensions. Spirituality like personality, character, temperament or health is an attribute of individual.

${ }^{1}$ PhD Student, Department of Psychology, Sardar Patel University, Vallabh-Vidyanagar

(C) 2015 I A Mahida; licensee IJIP. This is an Open Access Research distributed under the terms of the Creative Commons Attribution License (http://creativecommons.org/licenses/by/2.0), which permits unrestricted use, distribution, and reproduction in any Medium, provided the original work is properly cited. 


\section{The Role of Spiritual Psychology for Holistic Living}

Holistic living is the art of living in balance with our environment and us. Understanding and respecting that all things are interconnected is at the heart of a holistic lifestyle. Holistic living is about taking responsibility for our actions and choices in the knowledge that these choices have consequences for all living things on the planet. Holistic living offers a way to balance your life in all areas -- health, relationships, spirituality, and finances to achieve a happier, healthier, and more fulfilling lifestyle. More romance, financial security, a healthier body, and a spiritual connection to the world are just some of the benefits of holistic living. Whether you are looking to live a cleaner, healthier lifestyle, provide better and healthier food for you and your family, improves your romantic relationships, or simply gains a sense of peace and connection to the universe, other people, and your immediate environment.

\section{SPIRITUALITY}

Gilder (1997) stated that the view of a spiritual dimension to human kind is receiving increasing support. Spirituality is a word used in an abundance of contexts that means different things for different people at different times in different cultures. Although expressed through religions, art, nature and the built environment for centuries, recent expressions of spirituality have become more varied and diffuse. The term "spirituality" has changed throughout the ages.

Spirituality is a state of consciousness that reflects engagement the deep and often urgent need to understand, a need to know. The state of consciousness can be characterized in biological as well as phenomenological terms. Spirituality like personality, character, temperament or health is an attribute of individual.

1) Spirituality brings a feeling of unity with nature and people. 2) Spirituality is an inner belief system, which concerns the essence of my being. 3) Spirituality develops a sense of higher consciousness that connects the creator and the created. 4) Spirituality helps people in reaching and exploring challenges, seeking personal truth, development the sense of unity of life and developing a personal philosophy. 5) Spirituality is refers to the relationship between others and me and between god and me. 6) Spirituality is unique to each individual, influenced by culture, development, experiences and ideas, meaning, transcendent, hope, love, quality, relationship and existence.

Huddleston (1992) defined Spirituality is the vision of who we are as human begins.

According to Wong (2006), Spirituality is the motivational emotional source of an individual's quest for a personally defined relationship with people and the non-human environment for it includes a connectedness with a higher being, leading to enhanced feeling of well being, inner peace and satisfaction.

According to the Bhagavat Gita, meaning spirituality means diving deep into inner self and realizing identity of our soul (Atman) the spirit within! It is only through path of spirituality 
human beings gained enlightenment (Kavalla jnana) and finally salvation (moksha).the stage enlightens can never be reached via path of religion, path of rituals!

\section{THE SPIRITUAL PSY CHOLOGY}

Spiritual psychology is a branch of psychology like child psychology and social psychology and a system of psychology like psychoanalysis. The study of consciousness as such in relation to thinking, mind and the sensing- brain constitutes the subject matter of spiritual psychology. Spiritual psychology is the science of being happy, complemented by new science and new biology, its foundation is the rock of ancient knowledge, it methodology is $21^{\text {st }}$ century art and its functionality enables perfect health, mind, body and soul. Science, art and spirituality unite creating a conscious vision through the purification of consciousness.

Spiritual psychology is the study and practice of art and science of human evolution in consciousness. Spiritual psychology walks with consciousness in both its depth, breadth. It has a sound basis in metaphysics, theoretical, and philosophical psychology and ancient philosophy combined with innovative science and the largest breakthrough in cellular biology. Spirituality helps us to heal our consciousness through self-development. It provides the tools and techniques for the process of reflection used to empower individuals to honestly review and learn from their own experiences. This is about learning from self and having the courage to own what feel and create.

On the surface, these two terms 'Spirit' and 'Psychology' seem to oppose each other. Typically, when we imagine anything spiritual we conjure images related to formlessness. Anything psychological would be mental, an aspect of the process of thinking. Spiritual Psychology directs attention to how these conditions support each other. In fact, how one cannot exist without the other. There is a relationship between thoughts and things. Things are the physical aspects of thoughts and thoughts are the mental aspects of things. No-thing can exist within the consciousness of any person absent of their ability to think about it. The more capable you are of discerning details (thinking), the more of any-thing you can see. Therefore, how humans manifest material items, relationships, health is by thinking things into existence.

According to the divine science school (2004) Washington Dc, Spiritual psychology is an examination of the relationship between human and divine mind and role of mind in attracting abundance, achieving inner serenity and spiritual growth.

Akbar Husain (2005) defined the field of spiritual psychology focuses on understanding the ways of spiritual fullness (e.g. believing in sacredness, unity and transformation), the knowledge of the self use of prayer, meditation, spiritual practices as the techniques for the treatment, assessment of spiritual diseases etc. This field is unified in two respects the first one is linking body, mind, heart spirit and secondly it established the relationship between theory and practice. 
K.Ramakrishna Rao (2005) stated Spiritual psychology is the study of mind/consciousness at the point of science religion interface. Spiritual psychology is the discipline that studies the way of knowing and realizing the self. Indian tradition it is asserted as atmanam viddhi.The duty is to know the self. Spiritual psychology aspires for total transformation of the person to achieve higher levels of awareness and excellence.

According to research by Frankl (1962), they both exceed other aspects of positive psychology toward its highest reach. Therefore, search for meaning of life is a key part of positive psychology, which is interested in the psychic health and satisfaction, psychological aspects of quality of life, positive emotionality and experiencing, and its equivalent personality dimensions such as happiness, overwhelming feeling, hope, modesty.

Steve Rother stated twelve paradigms of the field in his book 'The spiritual psychology'- Focus on Empowerment, Healing by Request, Intent, Perception, and Truth. Balanced Ego, Discernment, Creating Safe Space, Vulnerability, Mastery of Thought, Motivation and Responsibility.

\section{SPIRITUALITY AND MENTAL HEALTH}

Spiritual health is an important as the physical, social and mental health depends on our meaningful life and success in the world, but the spiritual health depends on our success and salivation both in this world. The spiritual health characterizes the growth of a believer in the fruit of spirit, which are love, joy, peace, grossness, gentleness, faith, meekness, temperance, righteousness and truth. Focus on specific health promoting behavior, spiritual exercise (i.e. meditation, prayer) is considered to modify the outcome criteria of wellness, as it is considered the gateway of realization; Meditation is scientific procedure for promoting cognitive growth by widening the horizons of consciousness.

Health, according to the World Health Organization's constitution, is 'a state of complete physical, mental and social well-being, not merely the absence of disease. The WHO report continues 'the health professions have largely followed a medical model, which seeks to treat patients by focusing on medicines and surgery, and gives less importance to beliefs and to faith in healing, in the physician and in the doctor-patient relationship.

In the mental health field, where stress is common to every kind of breakdown, the extraordinary protective effects of religion and spirituality are now just beginning to be recognized. For example:-

Depression-Overall, some $25 \%$ of women and $12 \%$ of men suffer major depressive disorder during their lifetime. However, people with a spiritual or religious affiliation are up to $40 \%$ less likely to get depressed than those who do not have such an affiliation. In addition, when they do get depressed, they recover faster. Where psychotherapy is offered, those receiving religiously orientated therapy sensitive to their religious beliefs score best on post-treatment measures. 
Depression among the medically seriously ill-Depression affects up to $35 \%$ of this group of patients. One study using multidimensional measures showed that for every 10-point increase in the intrinsic religion score, there was a $70 \%$ increase in the speed of remission from depression. Another study showed that the more severe the disability, the stronger the protective effect of religious commitment.

Suicide -Adults aged over 50 who have never participated in religious activities are four times more likely to commit suicide than those who do. This holds true after having adjusted for other variables. Similarly, religious commitment among teenagers significantly reduces the risk of suicide.

Substance Abuse-Religious/spiritual commitment correlates with lower levels of substance abuse. The risk of alcohol dependency is $60 \%$ greater when there is no religious affiliation. In one study of opiate withdrawal, $45 \%$ of participants in a religiously orientated program remained drug-free at one year compared with $5 \%$ in a non-religious treatment programme.Concerning alcohol abuse, those who participate in, which is spiritually orientated and invokes the help of a Higher Power, are most likely to remain abstinent after inpatient or outpatient treatment. Studies such as these surely tell us that there is far more to mental illness than the biological sciences can ever explain.

Spirituality and Psychiatry-The psychiatrists need to have clear aims and aspirations for the treatment of each individual patient. In order to benefit within British psychiatry, the notion of linking spirituality with psychiatry developed largely in the 21 st century. If the psychiatrist remembers to incorporate spiritual values into his or her clinical practice, he or she will need to ask the patient a few pertinent questions, thus taking spiritual history that assesses needs in this area. Spirituality of psychiatrists, the patient, and the psychiatrists required listening empathically and inevitably, he or she has values and standards that are applied, often unconsciously, in clinical practice. There has been much work on values in psychiatry over recent years, much of it pioneered by the Royal College of Psychiatrists Philosophy Special Interest Group and its founding chairperson (Fulford et al, 2006).

All psychiatrists should be trained to help colleagues with mental health problems, both within psychiatry and in other medical disciplines. Some psychiatrists, especially as they become more senior in their work, gradually develop existential or spiritual difficulties concerning their professional practice. If they cannot resolve these concerns and deal with their internal doubts, they become more prone to burnout and despondency.

Spirituality is increasingly being included as a component of psychiatric treatment and as an independent and dependent variable in treatment research. Furthermore, a variety of faith-based organizations is providing care for people with mental health problems (Koenig, 2005). Koenig proposed ten ways in which religion can improve mental health (2005). He includes within his analysis reference to spiritual as well as religious beliefs and we would extend the analysis here 
to explicitly refer to both throughout. Thus, spirituality and religion can help us to promote a positive worldview, help to make sense of difficult situations and to give purpose and meaning. It also helps one to discourage maladaptive coping, to enhance social support. to promote 'otherdirectedness, Help to release the need for control, provide and encourage forgiveness, encourage thankfulness and to provide hope.

Spiritual Psychotherapy-Spirit is the healer, the therapist and client are both patients resisting healing. In-and-outside sessions, a spiritual psychotherapist calls on a higher power in the mind through prayer to be present to facilitate the healing. The therapist is a patient, as is the client, who appeals to spirit as the inner guide-healer-therapist-doctor-teacher. The healing is already accomplished in mind, but the two are asking for help in learning forgiveness in order to recognize wholeness. Suffering due to separation from spirit starts to be undone.

The mental problems of the psychotherapist and the client are identical, and the two are different only in superficial bodily form. The client's resistance is the same as the therapist's and both need compassion and love, because both endure a lack of kindness in terms of self-forgiveness. Becoming "inspirited," a psychotherapist inspires self and other. The therapist endeavors to keep spirit conscious in the healing process, but either one, or both, may deny the freedom to join higher mind power.

The psychotherapist is responsible to spirit to change his mind and to perform "miracles," but is not responsible to the client to change his life or to reform the profession. The purpose of spiritual psychology and psychotherapy is to transcend the illusion of separation, to escape the dominance of perception in thinking and to activate spirit in the life of the mind. The therapist and the client experience an interaction through spirit that diminishes personal suffering when learning forgiveness. Both the profession and the world, as illusions, can never be healed or reformed, but as its last stand, the ego will always contend that spirit is problematic.

Spiritual Counseling-The first step is recognizing our true self is to understand that each of us is spiritual beings. Our spirit guides us through life. Spiritual counseling is life coaching that helps awaken and revitalize our spirits, it help to give us direction in our everyday lives to move ahead on our path to awakening and enlightment.It will allow you to see your life in a more light and spiritual way instead of just focusing on the physical attributes of life. It can help give you new personal perspective and vision. Spiritual counseling refers to such a service when the advice or guidance provided is based on spiritual principles.

The role of Spiritual Counselors -1) To assist counselee in strengthening his connection to his divine Source resulting in receiving perfect answer for him. 2) To be truly helpful by allowing counselee the freedom to explore and share what is in his mind and heart. 3) To heal the painful and difficult problems of life with love, passion and integrity.4) To heal emotional trauma and abuse.5) To know unique purpose in the world and how to achieve it.6) to help and develop a 
clear and realistic plan with god to accomplish a career and personal goals.7) Release guilt, fear and other emotions and limiting beliefs, 8) to give practical advice to counselee on how to heal his personal relationship.

Spiritual Counseling can help you to find answers within our self instead of being dependent on someone else to give us answers, people that need to have some inner reflection will find this to be quite beneficial. Spiritual counseling helps to the counselee in personal growth in terms of feeling completely restored and filled with peace, to develop stronger sense of connection with god, our self deeper understanding of how the life circumstances are presently serving and to know all the questions fully answered, regardless of their nature (I.e. personal and social) profound knowingness of how loved and acceptance truly are in god's eye.

Spirituality at work place- The work place spirituality recognizes that people have inner life that nourishes by meaningful work that takes place in the context of community (Ashmos \& Duchon, 2000). It would mean that work would move from merely being a place to get enough money to survive - from just earning our daily bread to being a place of livelihood. The topic of spirituality is gaining importance among academicians as well as business professionals currently. Spirituality is extensively incorporated either tacitly or explicitly in public or private, and profit or nonprofit organizations across the world.

\section{CONCLUSIONS}

Our happiness is a result of our commitment to follow our path, to listen to our truth. As opportunities for growth are presented to us, we have the ability to walk forward into life with our eyes open, in order to understand and assimilate the inner significance of our outer challenges. The aim of this paper was to review and analyze the growing body of spirituality with particular attention to determining the nature and aims of spirituality for holistic living. Somewhere it may explore the role of spirituality and spiritual psychology in health care services, mental health, psychiatrist treatments and counseling.

Further, the main purpose of this paper is to understand the effect of spirituality on mental health. The role spirituality and spiritual psychology like other fields of psychology to understand how and to what degree people integrate their personal faith identity and its psychology manifestations to live a healthier life. Spirituality and faith at work can help practitioners to work better within the field.

\section{REFERENCES}

Ashmos, D. \& Duchon, D. (2000). Spirituality at Work. A Conceptualization and Measure.

Danesh, H. B. (1994). The psychology of spirituality: From divided self to integrated self. Victoria, Canada: Paradigm Publishing. 
Fulford KWM, Thornton T \& Graham G.(2006). Oxford Textbook of Philosophy and Psychiatry. Oxford University Press.

Gilder, G. (1997). The materialist superstition. Seattle, WA: Discovery Institute for Public Policy. Retrieved December 1999,

Hussain, A.(2005).Spiritual Psychology, Global vision publishing house, New Delhi

Husain, A. (2011).Spirituality and Holistic Health: A Psychological Perspective. New Delhi, Prasad Psycho Corporation, ISBN: 978-81-909923-3-6

K.Ramakrishna Rao \& Sonali Bhatt-Marwah.(2002).Towards a spiritual Psychology: Essays in Indian psychology (pp. 169-209). New Delhi

Koenig, H. G. (2005) Faith and Mental Health. Templeton

Koenig, H. G., McCullough, M. E. \& Larson, D. B. (2001) Handbook of Religion and Health. Oxford University Press

Royal College of Psychiatrists (2007) www.rcpsych.ac.uk/spirit

Swinton, J. (2000). '10. The Spiritual Dimension of Pastoral Care: Practical theology in a multidisciplinary context'. Jessica Kingsley Publishers

Steve Rother \& Sandra Sedgbeer.(2006). Spiritual Psychology: The Twelve Primary Life Lessons: Information for Facilitators of Human Evolution,_Light worker Publications

World Health Organisation WHOQUOL and Spirituality, Religiousness and Personal Beliefs: Report on WHO consultation Geneva: WHO 1998 